\title{
The Effect of the Holding Pressure Profile on the Metal Injection Molded Component Dimensions after Sintering
}

\author{
Emir Šarić ${ }^{*}$ Samir Butković, Muhamed Mehmedović
}

\begin{abstract}
The volumetric flow rate (injection velocity) and the holding pressure are metal injection molding (MIM) parameters that have a strong influence on the green parts density and density homogeneity, but their effect on sintered dimensions after sintering is still to a large extent unexplored. To reveal the relationship between the injection molding parameters and sintered dimensions, ring-shaped components were injection molded by using different values of injection velocities in combination with a rump-down and rumpup holding pressure profile. Afterwards, the green components were catalytically debound and sintered in the nitrogen $\left(\mathrm{N}_{2}\right)$ atmosphere. Finally, the component dimensions: the height, inner and outer diameter were measured by using a coordinate measuring machine. The ready-to-mold granules Catamold $310 \mathrm{~N}$ made of heat resistant stainless steel X40CrNiSi 25-20 (according to the EN standard) powder and polyacetal based binder were used. The results showed that the interaction between the injection velocity and the holding pressure profile can be used to systematically adjust shrinkage after sintering. This approach is based on the dependence of the binder crystallization temperature on pressure, when the powder/binder proportion changes with the injection velocity.
\end{abstract}

Keywords: dimensional control; holding pressure profile; metal injection molding; shrinkage

\section{INTRODUCTION}

In recent times, MIM has been recognized as a technology for net shape production of small metallic components with complexity that can be achieved by injection molding techniques. The major technological phases of MIM, when producers rely on the commercial granulated mix of metallic powder and binder (feedstock) are:

- injection molding, where melted feedstock is transferred, pressurized and cooled in mold cavities forming the socalled green component,

- debinding, where most of the binder is removed from the green component to get a shaped porous and dominantly metallic part,

- and finally sintering, where the porosity and the part dimensions are significantly reduced at the sintering temperature to achieve metallic parts with a density of $96 \%$ or more.

Owing to the high solid loading (typical powder content $60 \%$ vol.), MIM feedstocks have the thermal conductivity and the viscosity one order higher, and the heat capacity about three times lower than plastic $[1,2]$. Therefore, the injection molding of the MIM feedstock is more temperature sensitive and requires higher injection rates and pressures compared to plastic. Moreover, the MIM feedstock flowability is affected by the phenomena such as metal particle migration from a high to low shear rate region [3], powder agglomeration and powder-binder segregation in the runner and cavities. The density inhomogeneity induced in the injection molding phase cannot be rectified in subsequent processing steps. The industry standard for the dimensional precision in MIM is in the range from $\pm 0.3 \%$ to $0.5 \%$ of the nominal dimensions [4]. The injection velocity and the holding pressure are the most important parameters of the injection molding phase for the dimensional precision of the final MIM components $[5,6]$.

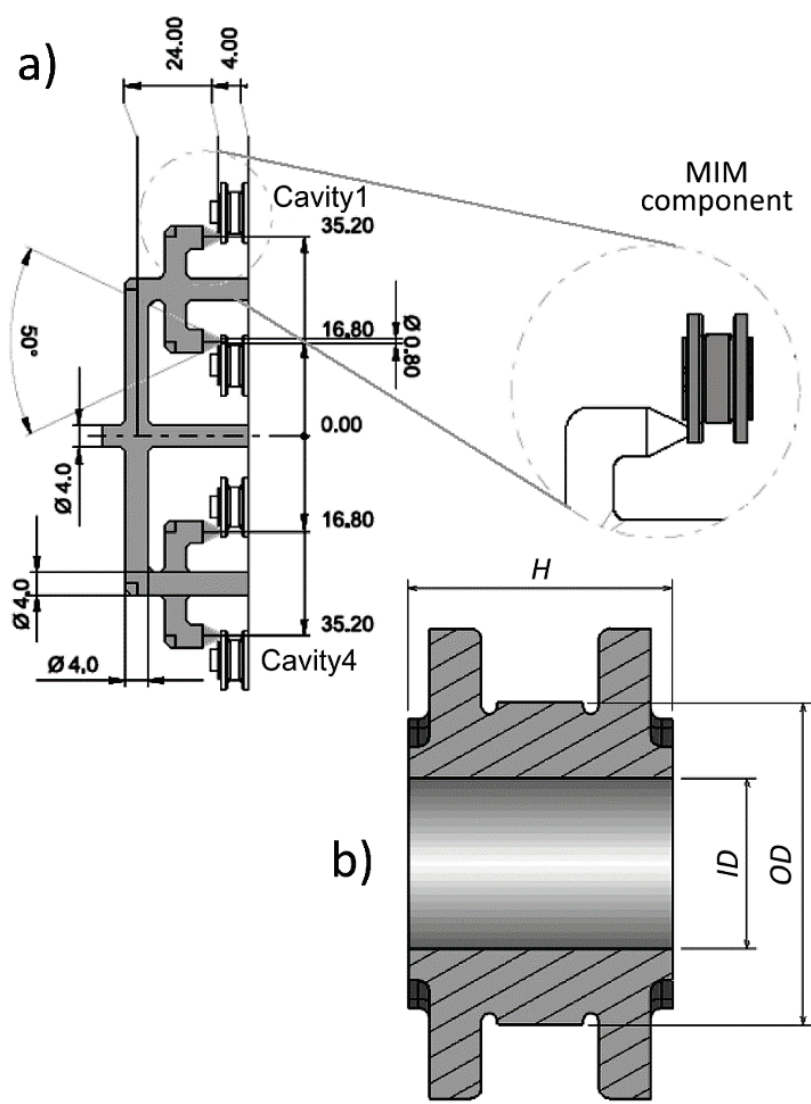

Figure 1 The runner system design and dimensions with the Pin-point gate location-detail and characteristic dimension: width $(H)$, inner diameter $(I D)$ and outer diameter $(O D)$

The amount of melted feedstock packed in a cavity depends on the packing intensity and packing time. Generally, the higher the cavity pressure-time integral is, the higher the packing intensity will be. The packing time lasts from the velocity/pressure $(v / p)$ switchover point to the moment the gate is completely crystallized. The binder crystallization temperature is sensitive to the variation of 
powder concentration, melt pressure and temperature. As a pure polymer, the MIM feedstock will crystallize at higher temperatures when pressure is applied, according to the pressure-volume-temperature (PVT) characteristic [7, 8]. However, increased metallic powder concentration (solid loading) in feedstocks diminishes the pressure sensitivity and shifts the feedstock crystallization point toward lower temperatures $[8,9]$.

Owing to the feedstock sensitivity to the injection, parameters' change and the complex interconnection between the technological phases, the influence of injection parameters in the final part quality in MIM remain to a large extent an unexplored territory. With this motivation in mind, the current paper researches the interactive effects of the holding pressure profile and the volumetric flow rate (injection velocity) on the final dimensions' change.

\section{EXPERIMENTAL WORK}

Green components were molded in a four-cavity split mold with a vertically positioned runner system by using pinpoint gates, Fig. 1a. The studied components were ringshaped with an external groove in the middle, with the nominal mass after sintering of $1.27 \mathrm{~g}$, Fig. $1 \mathrm{~b}$.

\subsection{Material}

The material used in this research was a highly viscous feedstock Catamold $310 \mathrm{~N}$, with high crystalline polyacetal based binder, produced by BASF, Fig. 2. The reported oversize factor (tool dimension/sintered dimension) has the nominal value of 1.1669 with a variation range of \pm 0.004 based on a long term batch-to-batch variation.

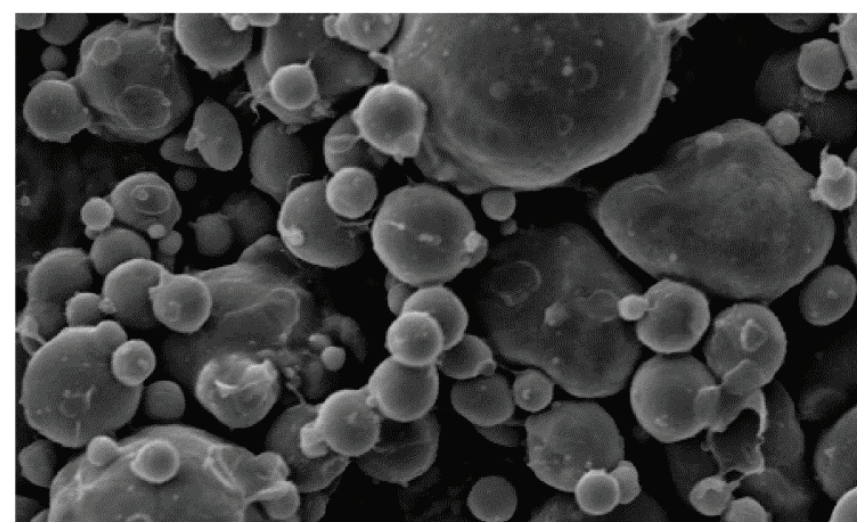

Figure 2 Etched surface of the green part (metal powder and residual binder) Catamold 310N, 1000x

\subsection{Injection Molding}

The Arburg 320C injection molding machine adopted for the MIM process with a low compression screw $(\varnothing 20 \mathrm{~mm})$ was used in injection experiments. The feedstock was plasticized by using the constant values of the screw speed of $30 \mathrm{rpm}$ and the back pressure of $30 \mathrm{bar}$, while the barrel temperatures from the feeding zone to the nozzle were 160 ${ }^{\circ} \mathrm{C}, 170{ }^{\circ} \mathrm{C}, 180{ }^{\circ} \mathrm{C}$ and $190{ }^{\circ} \mathrm{C}$. The cooling fluid temperature of $115^{\circ} \mathrm{C}$ was maintained by two "Regloplas" tempering units, where two insulating plates were placed at the tool/machine interface to improve temperature uniformity.

The injection velocity and the holding pressure profile are variables used in injection experiments. Both of them have the influence on the green part density [10-12] and consequently, on the dimensions after sintering [13]. The choice of parameters' variation ranges was based on the mold filling study, where the main criteria was to produce defect free green parts.

At first, the runner system was filled with $10 \mathrm{~cm}^{3} / \mathrm{s}$, then velocity was reduced and varied in range from 5 to $7 \mathrm{~cm}^{3} / \mathrm{s}$ to avoid excessive shear heating in the gates area. The cavities were continued to be filled under reduced velocity until the switchover volume was reached. Then, the achieved injection pressure (with an average value of 1300 bar) was rapidly reduced to the packing phase of the initial pressure of 850 bar in $0,05 \mathrm{sec}$. Afterwards, the packing pressure was changed by using the rump-down ( 800 to 850 bar) and rumpup ( 850 bar to 900 bar) profiles, Fig. 3. It was found that the holding time of $2.1 \mathrm{sec}$ was sufficient to assure gate crystallization (sealing) and prevent the back flow effect.

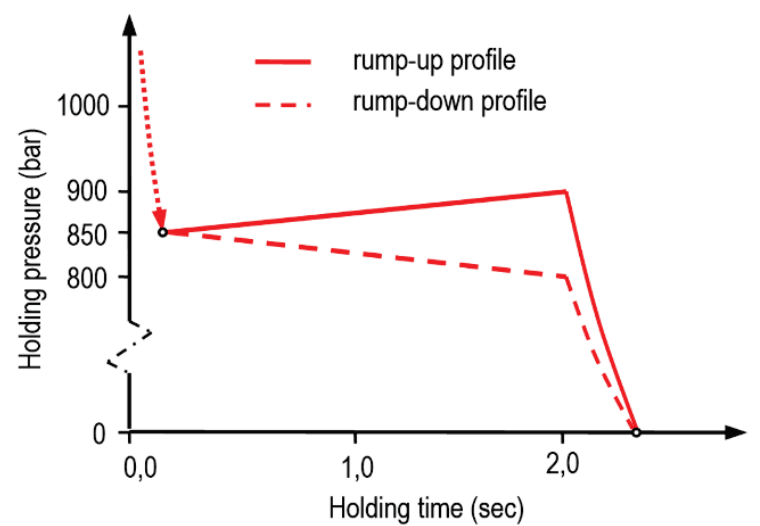

Figure 3 Holding pressure profiles used in injection experiments: "Rump-down" linear profile from 800 to 850 bar and "Rump-up" linear profile from 850 to 900 bar

Twenty injection cycles were performed between each parameter's change to assure that the parameters' change affected the process.

\subsection{Debinding and Sintering}

The green parts were placed on ceramic $\mathrm{Al}_{2} \mathrm{O}_{3}$ plates to prevent the diffusion between the samples and the supporting molybdenum shelves. Afterwards, the debinding process was performed in an Elnik $3002 \mathrm{CE}$ oven at a temperature of 110 ${ }^{\circ} \mathrm{C}$ in $\mathrm{ANO}_{3}$ rich atmosphere (>98\%), according to the BASF process. The oven was supplied with $500 \mathrm{l} / \mathrm{h}$ pure nitrogen during the entire cycle. This catalytic debinding technique assured very fast binder degradation from the surface to the green parts' core. After debinding, the brown parts were replaced in an Elnik batch water cooled furnace MIM_3002, where one step thermal debinding and sintering took place. The density of the $\mathrm{N}_{2}$ atmosphere lowered via the partial pressure of 400 mbar assuring the laminar flow over 
the components' surface and temperature uniformity during the process. At first, the back-bone polymer (polyolephin) was completely burned in one hour at $600^{\circ} \mathrm{C}$, then sintering was performed in three hours at $1310^{\circ} \mathrm{C}$. The temperatures in six different furnace zones were kept in range from \pm 3 to $\pm 7^{\circ} \mathrm{C}$ during the sintering cycle.

\subsection{Evaluation of the Sintered Parts}

After sintering, the characteristic dimensions: the width $(H)$, inner diameter $(I D)$ and outer diameter $(O D)$ were measured by a Coordinate Measuring Machine (CMM). For the purpose of the analysis, three sintered components per cavity (upper cavity 1 and lower cavity 4, Fig. 1a) were selected from the components' groups produced by using six different molding conditions. The average variation coefficients of sintered dimensions obtained with the same molding conditions were below $0.1 \%$.

\section{RESULTS AND DISCUSSION}

To compare the results obtained by using different holding pressure profiles, the means with the \pm standard deviation (SD) for the part width, inner and outer diameter after sintering vs. the injection velocity were plotted on bar graphs.

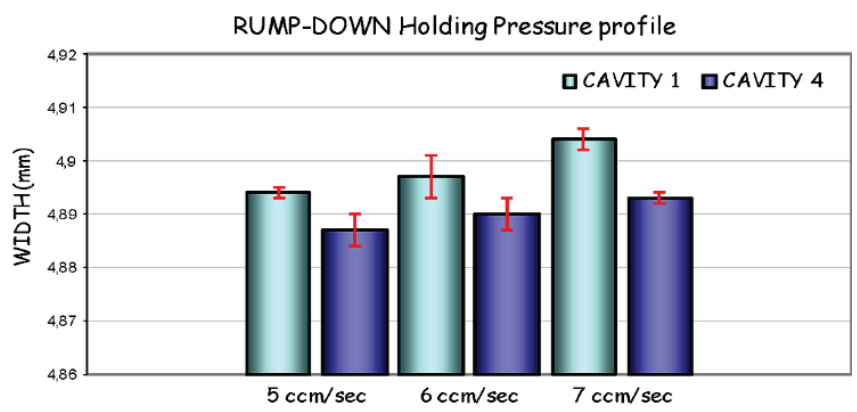

INJECTION VELOCITY

RUMP-UP Holding Pressure profile

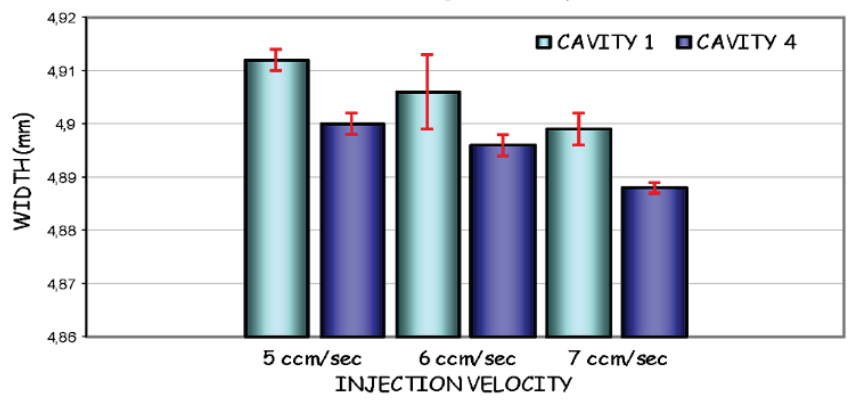

Figure 4 Sintered widths (mean $\pm S D$ ) obtained with a rump-down and rump-up holding pressure profile

The injection velocity and $H$ correlation were a strong positive when the rump-down profile was used, with $(r=$ $0.887 ; p=0.001)$ for cavity 1 and $(r=0.81 ; p=0.008)$ for cavity 4 . However, with the rump-up profile, this correlation became a strong negative with $(r=-0.832 ; p=0.005)$ for cavity 1 and $(r=-0.959 ; p=0.000)$ for cavity 4 , Fig. 4. Similar results were obtained for the correlation between the injection velocity and $O D$ after sintering. Namely, a very strong positive correlation for cavity $1(r=0.825 ; p=0.006)$ and a strong positive for cavity $4(r=0.696 ; p=0.037)$ were observed when the rump-down profile was used.

However, when the rump-up profile was used, this correlation was a moderate negative for cavity $1(r=-0.487$; $p=0.183)$ and a strong negative for cavity $4(r=-0.787 ; p=$ 0.012), Fig. 5.
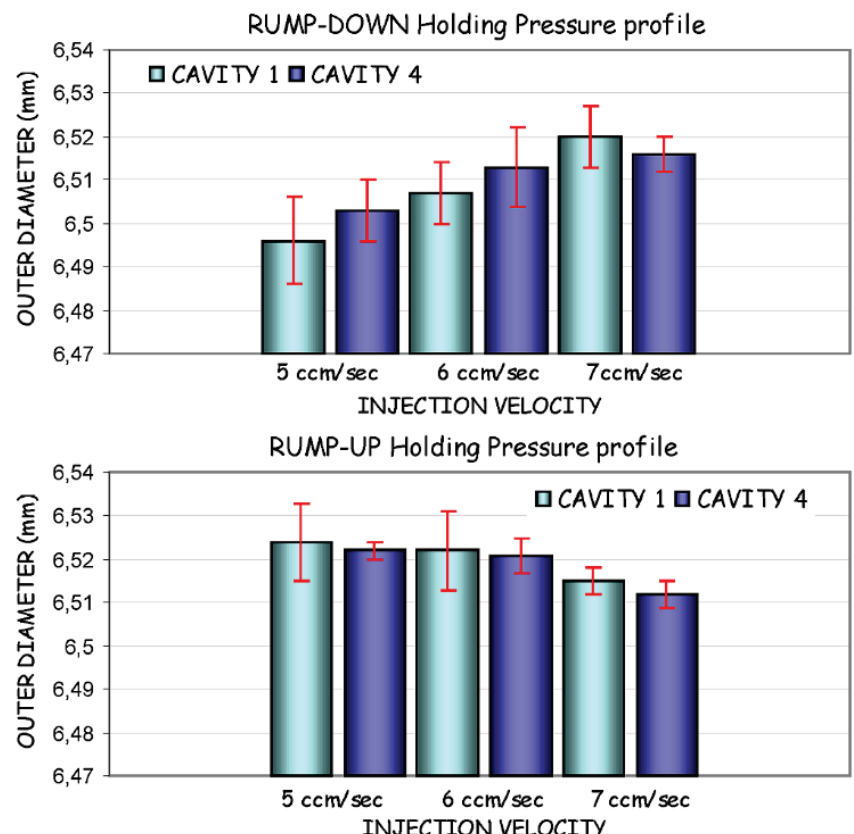

Figure 5 Sintered outer diameters (mean $\pm S D$ ) obtained with a rump-down and rump-up holding pressure profile

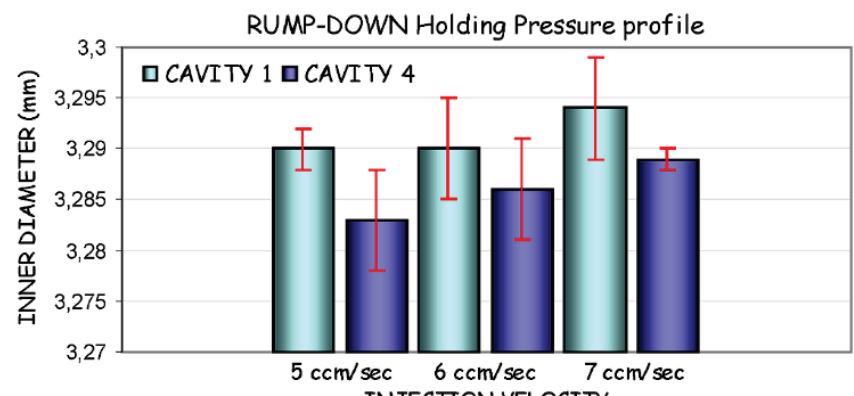
INJECTION VELOCITY

RUMP-UP Holding Pressure profile

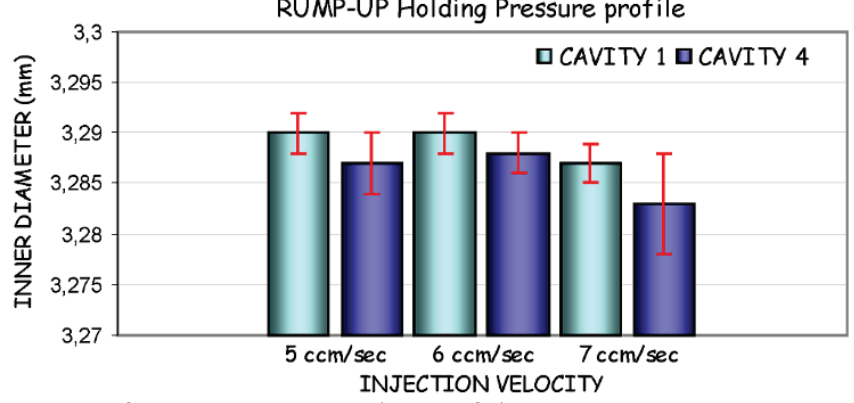

Figure 6 Sintered inner diameters (mean $\pm S D$ ) obtained with a rump-down and rump-up holding pressure profile

As for the inner diameter, the direction of obtained the relationship was the same, but with a moderate correlation for both cavities, Fig. 6 . 
The results showed that the average dimensions after sintering were positively correlated with the injection velocity when the rump-down holding pressure was used. As the injection velocity increases, the amount of shear heating, which is proportional to the square of the shear rate, also increases. Since the shear heat cannot be fully conducted away through the tool, the melt temperature rises. When the melt temperature is higher, the time until the gate has crystallized (effective packing time) is longer. Moreover, the higher the injection velocity is, the more intensive the packing will be. Subsequent packing pressure decreases from 850 bar to 800 bar, according to the MIM feedstock PVT characteristic, the binder crystallization temperature shifts toward lower values, causing additional prolongation of the effective packing time. The prolonged effective packing time due to the injection velocity increases and the holding pressure decrease is responsible for the obtained positive correlations.

However, in clear contrast with what we observed with the rump-down profile, the correlations became negative when the rump-up holding pressure profile was used. This can be explained by the pressure influence on binder crystallization. Namely, the holding pressure increases the shifts of the feedstock crystallization temperature toward higher values when the solid loading is sufficiently decreased [9]. Higher crystallization temperature causes earlier gates' sealing and consequently, the reduction of the effective packing time. Shear heating and powder segregation in the runner system with the velocity led to the lowering of the feedstock solid loading, which is the prerequisite for such feedstock behavior.

\section{CONCLUSION(S)}

The Catamold $310 \mathrm{~N}$ feedstock batch-to-batch shrinkage factor variation range $( \pm 0.004)$ produces the variation of the sintered part dimensions from the nominal of about $\pm 0.34 \%$. This variation and inevitable machining error of the cavities consume almost the entire MIM tolerance budget without taking into account the variation induced in the processing steps. Producers relying on commercial feedstock do not have the ability to adjust the shrinkage factor by changing the feedstock formulation. Thus, to maintain the narrow part' tolerances, they often have to rework the mold cavities for new batches or they have to introduce post-sintering operations.

The results presented in this research prove that the input process variables - injection velocity and holding pressure could be used to systematically control the shrinkage factor in MIM. Namely, the results showed the shrinkage factor decrease with the velocity for all dimensions with an average value of $0.002 \mathrm{~mm} / \mathrm{mm}$, after the application of the rumpdown holding pressure profile from 800 to 850 bar. When the rump-up pressure profile from 850 bar to 900 bar was applied, the results showed an average shrinkage factor increase with the injection velocity of about $0.0017 \mathrm{~mm} / \mathrm{mm}$. The obtained shrinkage factor changes were evaluated as significant since they cover about $50 \%$ of the reported batchto-batch shrinkage range.

These findings reveal a new low cost approach to compensate for the batch-to-batch shrinkage factor variation and the variation due to the reuse of feedstock that could be valuable for MIM parts' producers who rely on commercial feedstocks.

\section{REFERENCES}

[1] Martin, M. (1999). Powder Injection Moulding of Metals, Ceramics and Metal Matrix Composites. Materials World, 7(2), 71-75.

[2] Bilovol, V. V. (2003). Mold filling simulation during powder injection moulding. PhD Thessis, Delft University of Technology, delft, Netherlands.

[3] Kim, C. (2001). Migration in concentrated suspension of spherical particles dispersed in polymer solution. KoreaAustralia Rheology Journal, 13(1), 19-27.

[4] German, R. M. (2004). Green Body Homogenity Effects on Sintered Tolerances. Journal Powder Metalurgy, 47(2), 157160. https://doi.org/10.1179/003258904225015563

[5] Luo, T. G., Qu, X. H., Qin, M. L., \& Ouyang, M. L. (2009). Dimension precision of metal injection molded pre tungsten. International Journal of Refractory Metals \& Hard Materials, 27(3), 615-620.

https://doi.org/10.1016/j.jirmhm.2008.10.003

[6] German, R. M. (1996). Statistical analysis of shrinkage variation for powder injection molding. Journal of Material Processing Technology, 59, 278-284. https://doi.org/10.1016/0924-0136(95)02158-2

[7] Cucarella, M. C. M. (1982). Effects of high pressure on polymer crystallization. Latin American Journal of Metallurgy and Materials, 2(1).

[8] Hausnerova, B., Sedlacek, T., Slezak, R., \& Saha, P. (2006). Pressure dependent viscosity of powder injection moulding compounds. Rheol Acta, 45, 290-296. https://doi.org/10.1007/s00397-005-0036-4

[9] Chandra, A., Best, A., Meyer, W. H., \& Wegner, G. (2009). P$\mathrm{V}-\mathrm{T}$ measurements on $\mathrm{PMMA}: \mathrm{PbTiO}_{3}$ polymer-ceramic composites with tunable thermal expansion. Journal of Applied Polymer Science, 115(5). https://doi.org/10.1002/app.29819

[10] Petera, P. (2012). Holding pressure and its influence on quality in PIM technology. Acta polytehnica, 52(4). https://doi.org/10.17973/MMSJ.2012_07_201208

[11] Islam, A., Hansen, H. N., \& Rasmussen, T. T. (2013). Effects of holding pressure and process temperatures on the mechanical properties of molded metalic parts. ANTECH 2013 Conference Proceedings, Society of Plastic Engineers Incorporated.

[12] Tseng, W. J. (1988). Statistical analysis of process parameters influencing dimensional control in ceramic injection molding. Journal of Material Processing Technology, 79(1-3), 242-250. https://doi.org/10.1016/S0924-0136(98)00019-3

[13] Green, C. D. \& Heaney, D. F. (2007). The PVT effect on final sintered dimensions of powder injection molded components. Materials and Design, 28, 95-100. https://doi.org/10.1016/j.matdes.2005.05.023 


\section{Authors' contacts:}

Emir Šarić, PhD, Associate Professor

University of Tuzla,

Faculty of Mechanical Engineering,

Univerzitetska 4, 75000 Tuzla, Bosnia and Herzegovina

E-mail: emir.saric@untz.ba

Samir Butković, PhD, Associate Professor

University of Tuzla,

Faculty of Mechanical Engineering,

Univerzitetska 4, 75000 Tuzla, Bosnia and Herzegovina

E-mail: samir.butkovic@untz.ba

Muhamed Mehmedović, PhD, Associate Professor

University of Tuzla,

Faculty of Mechanical Engineering,

Univerzitetska 4, 75000 Tuzla, Bosnia and Herzegovina

E-mail: muhamed.mehmedovic@untz.ba 